\title{
Queijo Parmesão: caracterização físico-química, microbiológica e microestrutura
}

\author{
Parmesan cheese: physicochemical and microbiological quality and microstructure
}

\author{
Jupyracyara Jandyra de Carvalho BARROS ${ }^{1}$, Analice Cláudia de AZEVEDO ${ }^{1}$, \\ Luiz Roberto FALEIROS JÚNIOR ${ }^{1}$, Sebastião Roberto TABOGA², Ana Lúcia Barretto PENNA ${ }^{1 *}$
}

\begin{abstract}
Resumo
Mudanças no queijo Parmesão durante a maturação podem ser avaliadas por análises químicas, microbiológicas e microscópicas. Este estudo teve por objetivo efetuar a caracterização físico-química e microbiológica do leite e do queijo Parmesão, assim como sua microestrutura, durante 180 dias de maturação. Todas as amostras exibiram características físico-químicas e microbiológicas de acordo com a legislação brasileira. Ocorreu aumento na acidez titulável, nos índices de extensão e profundidade da maturação e nos teores de tirosina e triptofano. A análise da microestrutura demonstra a presença de cristais, debris, e a interação entre as culturas starter e os glóbulos de gordura. No final da maturação, a matriz de caseína apresentava-se densa e compacta.
\end{abstract}

Palavras-chave: Parmesão; maturação; microestrutura.

\begin{abstract}
Changes in Parmesan cheese during ripening can be detected by chemical, microbiological, and microscopic analysis. This study aimed to evaluate the physicochemical and microbiological quality of milk and cheeses, as well as to evaluate the microstructure of Parmesan cheese during 180 days of ripening. All samples exhibited physicochemical and microbiological characteristics in accordance with the Brazilian standards. There was an increase in titratable acidity, depth, and extension ripening indices, and also in the tyrosine and tryptophan contents. The microstructure analysis showed the presence of crystals, debris, and interactions between starter cultures and fat globules. At the end of the cheese ripening process, a dense and compact casein matrix was observed.

Keywords: Parmesan; ripening; microstructure.
\end{abstract}

\section{Introdução}

No Brasil, parte da produção leiteira é direcionada aos laticínios para a fabricação de queijos. Em 2008 foram produzidos 668 mil toneladas de queijos, sendo 32 mil toneladas de queijo Parmesão (ASSOCIAÇÃO..., 2010). Do consumo per capita de queijos, de aproximadamente $3 \mathrm{~kg}$ por ano (INSTITUTO..., 2006), 32,04\% é de Mussarela, 9,61\% de Prato, 7,96\% de Minas e 5,64\% de Parmesão. Este produto é o primeiro dentre as variedades de queijos especiais mais consumidos, podendo ser comercializado sob formas íntegras e fracionadas; entretanto, é geralmente consumido pela população na forma ralada.

O queijo Parmesão pode ser fabricado com leite in natura ou pasteurizado e/ou reconstituído padronizado (BRASIL, 1997). É um queijo semigordo, apresenta baixo teor de umidade, consistência dura, textura compacta e granulosa, com crosta espessa de 4 a $8 \mathrm{~mm}$, lisa e cor amarelo-palha. É um queijo ligeiramente picante e salgado, com odor suave e agradável; apresenta forma cilíndrica e peso oscilando entre 5 e $10 \mathrm{~kg}$. A temperatura de armazenamento não deve exceder $18{ }^{\circ} \mathrm{C}$ e deve ser maturado por cerca de seis meses (BRASIL, 1997). O rendimento da fabricação é em torno de $13 \mathrm{~kg}$ de leite. $\mathrm{kg}^{-1}$ de queijo após sua completa maturação (PERRY, 2004).
Para a fermentação, utilizam-se bactérias ácido-láticas termofílicas, geralmente compostas por Lactobacillus helveticus e Streptococcus thermophillus, sendo a coagulação da massa realizada à temperatura de $35{ }^{\circ} \mathrm{C}$ (McSWEENEY, 2004; FURTADO, 2005). Esta temperatura propicia o desenvolvimento das células láticas (KENNY et al., 2003; MARILLEY; CASEY, 2004) e mantém ativo o complexo enzimático endógeno (LORTAL; CHAPOT-CHARTIER, 2005; KELLY; FOX, 2006). As enzimas microbianas atuam, incisivamente, sobre o carboidrato, a gordura e as proteínas presentes no leite, potencializando os atributos sensoriais de textura, aroma e sabor, típicos desse produto. Além disso, as bactérias ácidoláticas são capazes de competir ou inibir a proliferação de patógenos e micro-organismos oportunistas (OGUNBANWO; SANNI; ONILUDE, 2003; BROMBERG et al., 2004), auxiliando na estabilidade físico-química desse produto.

Métodos objetivos - como os diagnósticos eletromicrográficos (ARYANA; HENK, 2004) e a precipitação fracionada das proteínas (MADADLOU; KHOSROSHAHI; MOUSAVI, 2005) - têm sido empregados para determinar o grau de maturação em queijos (PEROTTI et al., 2004). O 
emprego da microscopia óptica e eletrônica de transmissão MET (FRAU et al., 1997) tem sido adotado como ferramenta adicional para avaliar a qualidade e/ou defeitos em queijos maturados.

Nos períodos que antecedem a atividade proteolítica, a matriz caseínica apresenta caráter elástico; entretanto, no decorrer da maturação, a ação conjunta das proteases e peptidases resulta em uma característica mais rígida da matriz (LAWRENCE; GILLES; CREAMER, 1983). A compactação da microestrutura é decorrente da redução gradual da umidade, causada pela evaporação da água na superfície do queijo (McSWEENEY, 2004). Observações do coágulo do queijo por microscopia eletrônica indicam que a população de bactérias está diretamente relacionada com o conteúdo de gordura no queijo. Laloy et al. (1996) observaram que as populações da cultura lática eram de 30 a 100\% maiores e de quatro a 10 vezes maiores em queijos Cheddar com redução de $50 \%$ de gordura e em queijos Cheddar integrais, respectivamente, quando comparados com queijos Cheddar sem gordura.

Em queijos maturados por longos períodos, é comum detectar culturas láticas lisadas, sendo visível a formação de debris, que se caracterizam pela formação de dobras na célula morta, não absorvidas pela matriz do queijo (PAGALA et al., 2002). Ainda, nesses queijos, também é constante a incidência de cristais de fosfato de cálcio, lactato de cálcio e tirosinato de cálcio. As diferentes interações da lactose e outros componentes distribuídos nos queijos apresentam elevada complexidade e podem afetar a qualidade do produto final (PERKO, 2002). Em contrapartida, Furtado (2005) menciona que a presença de cristais de tirosina reflete o aspecto positivo das reações proteolíticas durante o período de estocagem. A ultraestrutura do queijo Grana maturado por 14 meses foi estudada por Bottazzi, Battistotti, Bianchi (1982) a partir da análise em microscópio eletrônico de varredura - MEV e raio X. Inclusões cristalinas de fosfato de cálcio, apresentando de 10 a $20 \mathrm{~nm}$, foram encontradas em queijos maturados por oito e 10 meses. Nas amostras maturadas por 10 meses, foram encontrados de 30 a 35 cristais. $\mathrm{m}^{-2}$. O surgimento de cristais é uma característica do queijo Grana, podendo ser encontrados desde dois dias a dois meses de maturação.

De acordo com Lopez (2005), a funcionalidade do queijo é influenciada pela concentração, pelo tamanho e pela forma dos glóbulos de gordura, bem como pela estrutura destes no leite fluido. Os lipídios se apresentam no leite como uma emulsão; contudo, sua microestrutura nos produtos lácteos e, particularmente no queijo, é pouco conhecida. Os glóbulos de gordura do leite podem ser alterados ou sofrer rupturas durante a fabricação dos queijos, em consequência dos tratamentos aplicados (YE et al., 2004). Segundo Mazerolles et al. (2001), a análise detalhada da microestrutura do queijo, especialmente das proteínas e gorduras, bem como as interações entre esses constituintes durante e após a produção do queijo, podem fornecer informações determinantes sobre a qualidade do produto final.

Candioti et al. (2002), em estudo realizado com queijo Reggianito Argentino elaborado com três diferentes cepas de Lactobacillus helveticus, verificaram que os teores de nitrogênio solúvel em TCA $12 \%$ diferiram ao longo de 180 dias de maturação e que o queijo fabricado com Lb. helveticus SF209 apresentou maior atividade peptidolítica quando comparada aos outros tratamentos. Malacarne et al. (2006) estudaram as alterações físico-químicas de queijo Parmigiano-Reggiano durante 96 meses e verificaram que durante os seis primeiros meses houve um aumento da proteólise, quantificada pela análise do nitrogênio solúvel em pH 4,6, sendo que após esse período este índice se manteve constante.

São poucos os trabalhos dedicados a relacionar os aspectos de qualidade de queijos brasileiros com o estágio de maturação. Neste estudo, o objetivo foi efetuar a caracterização físicoquímica, microbiológica e microestrutural do queijo Parmesão, durante 180 dias de maturação.

\section{Material e métodos}

\subsection{Amostras e caracterização físico-química}

Foram analisados três diferentes lotes $\left(\mathrm{L}_{1}, \mathrm{~L}_{2}, \mathrm{~L}_{3}\right)$ de leite pasteurizado e de queijo Parmesão comercial, fornecidos por uma mesma indústria (Figura 1), maturados a $12{ }^{\circ} \mathrm{C}$. Os parâmetros físico-químicos (densidade, gordura, sólidos totais e acidez) do leite empregado na fabricação de diferentes lotes

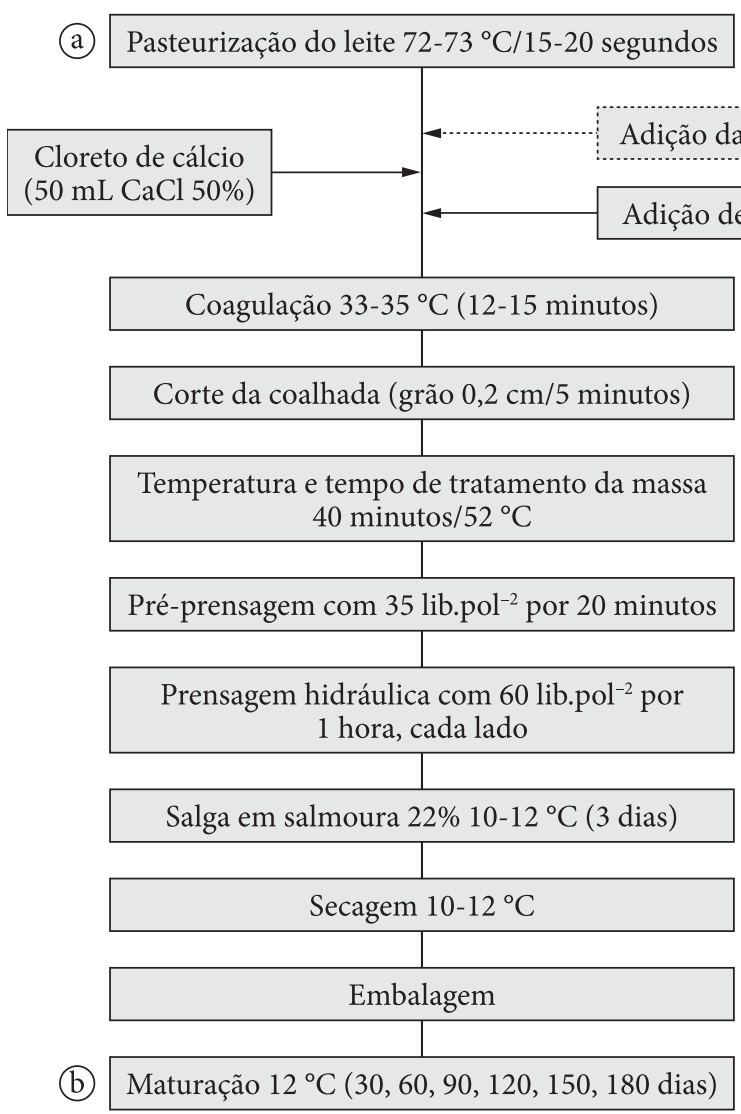

Figura 1. Fluxograma de fabricação das amostras comerciais de queijo Parmesão. a) coleta de amostras para análises físico-químicas e microbiológicas do leite; e b) coleta de amostras para análises físicoquímicas, microbiológicas e de microestrutura do queijo Parmesão. 
de queijo Parmesão foram determinados conforme normas analíticas do Instituto Adolfo Lutz - IAL (1985). Para análise de resíduos de antibióticos e crioscopia, foram empregadas as metodologias propostas por Tronco (1997) e Silva et al. (1997), respectivamente. As amostras dos queijos foram avaliadas a cada 30 dias, durante 180 dias, perfazendo um total de 18 amostras. As culturas empregadas no processamento foram Lactobacillus helveticus e Streptococcus thermophilus.

Para a caracterização físico-química, as amostras dos queijos foram avaliadas durante a maturação quanto aos aspectos: acidez titulável (SILVA et al., 1997); atividade de água (VAN DENDER et al., 1995); teores de cinzas (INSTITUTO..., 1985); umidade (CASE; BRADLEY JUNIOR.; WILLIAMS, 1985); gordura e gordura no extrato seco (INSTITUTO..., 1985); proteína total (ASSOCIATION..., 1997); nitrogênio solúvel em pH 4,6 e nitrogênio solúvel em TCA 12\% (SILVA et al., 1997); sal (SILVA et al., 1997); índices de extensão e profundidade da maturação (WOLFSCHOON-POMBO, 1983), e concentrações de tirosina e triptofano (VAKALERIS; PRICE, 1959). Todas as análises foram efetuadas em triplicata.

\subsection{Qualidade higiênico-sanitária do leite pasteurizado e dos queijos}

Para avaliação da qualidade higiênico-sanitária do leite pasteurizado e dos queijos, inicialmente, foram realizadas diluições decimais das amostras. Em $9 \mathrm{~mL}$ de água peptonada 1\% estéril, foi adicionado $1 \mathrm{~mL}$ da amostra de leite, constituindo-se a diluição $10^{-1}$, a partir da qual foram realizadas diluições seriadas até $10^{-4}$. Para o queijo Parmesão, $10 \mathrm{~g}$ da amostra foram transferidos para $90 \mathrm{~mL}$ de citrato de sódio $2 \%$, constituindo-se a diluição $10^{-1}$. A partir desta, foram realizadas diluições seriadas até $10^{-10}$, utilizando $9 \mathrm{~mL}$ de citrato de sódio $2 \%$ como diluente. No leite pasteurizado, foi realizada a contagem de bactérias do grupo coliforme empregando meio de cultura cromogênico Compact Dry ${ }^{\circledR}$ EC (Nissui Pharmaceutical Co, Tókio, Japão), bactérias mesófilas, Staphylococcus coagulase positiva e verificação da presença de Salmonella sp. (SILVA; JUNQUEIRA; SILVEIRA, 2007). O aspecto higiênicosanitário do queijo foi avaliado a partir das mesmas análises, excetuando a investigação de micro-organismos mesofílicos e Salmonella sp. Os micro-organismos mesofílicos foram quantificados pela técnica de cultivo em profundidade. Um $\mathrm{mL}$ de cada diluição selecionada foi distribuído em placas estéreis, acrescentaram-se $15 \mathrm{~mL}$ de Ágar Padrão para Contagem - PCA (HiMedia Laboratories Pvt. Ltda, Índia) fundido e resfriado a $45^{\circ} \mathrm{C}$. Após completa solidificação, as placas foram incubadas invertidas a $37^{\circ} \mathrm{C}$ durante 48 horas. O resultado foi multiplicado pela recíproca da diluição e o valor expresso em unidades formadoras de colônias por mililitro da amostra (UFC. $\mathrm{mL}^{-1}$ ) (SILVA; JUNQUEIRA; SILVEIRA, 2007). Staphylococcus coagulase positiva foi avaliado pelo método de spreadplate em ágar Baird Parker - BP (HiMedia Laboratories Pvt. Ltda, Índia), depositando $0,1 \mathrm{~mL}$ de cada diluição sobre a superfície do ágar e, com o auxílio de um bastão de vidro tipo hockey flambado, o inóculo foi espalhado por toda a superfície do meio até a completa absorção. As placas foram incubadas invertidas a $37^{\circ} \mathrm{C}$ por 48 horas. Foram selecionadas as placas contendo entre $30 \mathrm{e}$ 300 colônias, selecionando as colônias típicas (negras com halo transparente) e atípicas (negras isentas de halo transparente). A partir destas, foram selecionadas três colônias de cada placa, que foram inoculadas em tubos contendo $1 \mathrm{~mL}$ de Caldo Brain Heart Infusion - BHI (Difco ${ }^{\mathrm{TM}}$ Laboratories, Detroit, EUA), os quais foram incubados a $37^{\circ} \mathrm{C}$ por 24 horas. Em seguida, os cultivos foram analisados em microscopia diferencial de Gram, analisados quanto à presença da enzima catalase e à capacidade de coagular o plasma sanguíneo (NewProv, Pinhais, Brasil), previamente ressuspendido em solução fisiológica estéril 0,85\% (solução de cloreto de sódio - $\mathrm{NaCl} 0,85 \%$ ). O resultado foi expresso em UFC. $\mathrm{g}^{-1}$ (SILVA; JUNQUEIRA; SILVEIRA, 2007). A análise de Salmonella sp. foi realizada apenas para as amostras de leite utilizando o kit Lateral Flow System Salmonella (Dupont Qualicon ${ }^{\mathrm{m}}$, Wilmington, EUA). Para a análise, $25 \mathrm{~mL}$ do leite foram adicionados a $225 \mathrm{~mL}$ do meio de enriquecimento DuPont ${ }^{\mathrm{tm}}$ Lateral Flow System Salmonella, seguida da incubação a $37^{\circ} \mathrm{C}$ por 24 horas. A seguir, uma alíquota da amostra enriquecida foi aplicada na fita de teste e a leitura foi realizada após 10 minutos. A presença de duas linhas vermelhas na fita indica presença de $10^{\circ}$ UFC. $\mathrm{mL}^{-1}$ de Salmonella sp. no leite (SILVA; JUNQUEIRA; SILVEIRA, 2007).

\subsection{Microestrutura do queijo Parmesão}

A avaliação da microestrutura foi obtida a partir do microscópio eletrônico de transmissão - MET, mensalmente, no período total de 180 dias. As amostras dos queijos maturados foram fixadas em solução de $2 \%$ de glutaraldeído e paraformaldeído em tampão 0,05 M Milloning durante 12 horas. A seguir, as amostras foram lavadas com tampão PIPES e fosfato, e pós-fixadas em uma solução de $2 \%$ tetróxido de ósmio $\left(\mathrm{OsO}_{4}\right)$ em tampão fosfato durante 1,5 horas. Em seguida, essas foram lavadas duas vezes com tampão fosfato e desidratadas em uma série graduada de acetona (30, 50, 70, 90 e 95\%, 15 minutos cada), e, posteriormente, em acetona absoluta três vezes, 15 minutos cada. As amostras desidratadas foram embebidas em meio Araldite ${ }^{\circledast}$ de baixa viscosidade (1Acetona:1Araldite) durante 16 horas, seguida de infiltração e inclusão em Araldite ${ }^{\circledR}$ por 2 horas a $37^{\circ} \mathrm{C}$ e polimerização por 48 a 72 horas em estufa a $60{ }^{\circ} \mathrm{C}$, para obtenção dos blocos. Estes foram seccionados usando um ultramicrótomo e as secções ultrafinas de $80 \mathrm{~nm}$ resultantes foram coradas com $4 \%$ uranil acetato e chumbo, para análise em microscópio eletrônico de transmissão LEO Zeiss 906 (Zeiss, Cambridge, Inglaterra) (adaptado de AWAD; ABDELHAMID; EL-SHABRAWY, 2002; DABOUR et al., 2005). Foi avaliada, qualitativamente, a incidência de proteínas, lipídios e bactérias, bem como sua interação na matriz dos queijos nos diferentes períodos de maturação.

O método de coloração histoquímica de von Kossa foi utilizado para verificar a concentração de cristais de cálcio na matriz dos queijos ao longo do período de maturação, empregando o microscópio óptico Olympus BX 60 (Olympus, Hamburg, Alemanha). A partir das secções obtidas, foram selecionados cinco campos aleatórios de cada lâmina. As 
imagens foram capturadas utilizando o Image Pro-Plus Software 4.5 Windows (Media Cybernetics Inc., Bethesda, Estados Unidos da América). Estas imagens foram submetidas à análise estereológica para determinação do volume relativo dos cristais $\left(\mathrm{VR}_{\mathrm{c}}\right)$. Este $\mathrm{VR}_{\mathrm{c}}$ foi multiplicado pelo peso $(\mathrm{kg})$ da amostra para obtenção do volume absoluto dos cristais (VA ), adotando que $1 \mathrm{mg}$ do queijo maturado tem volume aproximado de $1 \mathrm{~mm}$ (DEKLERK; COFFEY, 1978). O resultado foi expresso em cristais por quilograma de queijo (cristais. $\mathrm{kg}^{-1}$ ).

\subsection{Análise estatística dos resultados experimentais}

A análise de variância (ANOVA) das amostras foi realizada a partir de um delineamento inteiramente casualizado (DIC) em esquema fatorial $3 \times 6$ (lotes $\times$ tempos de maturação). Foi aplicado teste de Tukey para comparação das médias das amostras, considerando um nível de significância $\mathrm{p}<0,05$, utilizando-se o programa computacional SANEST - Sistema de Análise Estatística para Microcomputadores (ZONTA; MACHADO, 1996).

\section{Resultados e discussão}

\subsection{Caracterização físico-química do leite pasteurizado e do queijo Parmesão}

O leite apresentou ponto crioscópico com variação de $-0,534^{\circ} \mathrm{H} \mathrm{a}-0,535^{\circ} \mathrm{H}, 1,031$ g.mL ${ }^{-1}$ a 1,032 g. $\mathrm{mL}^{-1}$ de densidade, 8,92 a $8,93 \%$ de extrato seco desengordurado (ESD) e 3,25 a $3,26 \%$ de proteínas. Pela metodologia empregada, não foram detectados resíduos de antibióticos nas amostras de leite pasteurizado utilizado nos diferentes processamentos. Não foi observada diferença estatística significativa $(\mathrm{p}>0,05)$ entre os lotes (Tabela 1).

A acidez titulável média oscilou de $15,76 \pm 0,14{ }^{\circ} \mathrm{D}$ a $18,33 \pm 0,42^{\circ} \mathrm{D}(\mathrm{p}>0,05)$, demonstrando adequação da matériaprima destinada à produção do queijo Parmesão (FURTADO, 2005). O monitoramento da acidez do leite é importante para assegurar a estabilidade do derivado lácteo, sendo uma prática muito comum nas indústrias lácteas.

O teor de gordura do leite, devido à padronização da matéria-prima pela indústria queijeira, variou de $2,2 \pm 0,8 \%$ a $3,2 \pm 0,1 \%(\mathrm{p}>0,05)$. Geralmente, o queijo Parmesão é processado com leite apresentando teor de 2 a 2,5\%. De acordo com McSweeney e Sousa (2000), a concentração de lipídios no leite é importante para o sabor e o aroma do queijo, pois esse componente também é utilizado como substrato nas modificações bioquímicas do coágulo durante a maturação.

Houve diferença significativa $(p<0,05)$ na composição centesimal dos diferentes lotes de queijo Parmesão comercial analisados. No entanto, estas diferenças são consideradas normais para o processamento industrial (Tabela 2).

A atividade de água variou de 0,975 $\pm 0,01\left(\mathrm{~L}_{2}\right)$ a $0,979 \pm 0,01\left(\mathrm{~L}_{3}\right)$. Com intuito de evitar perda excessiva de água e consequente rachaduras na superfície, os queijos foram maturados e acondicionados em embalagens termoencolhíveis, justificando os dados obtidos.

O teor de umidade oscilou de 30,21\% $\pm 0,82\left(\mathrm{~L}_{3}\right)$ a $31,28 \%$ $\pm 0,79\left(\mathrm{~L}_{1}\right)$, com diferença significativa entre os lotes $(\mathrm{p}<0,05)$, mas atendendo aos padrões vigentes. Estes valores foram superiores aos relatados por Romani et al. (2002) para amostras de queijos Parmigiano-Reggiano embaladas em atmosfera modificada e armazenadas a $4^{\circ} \mathrm{C}$ durante 90 dias, cujos valores variaram de 28 a $29 \%$.

Nas amostras de queijo referente ao $L_{1}$, o teor de gordura foi estatisticamente semelhante ao $\mathrm{L}_{2}(\mathrm{p}<0,05)$, apresentando valor de $28,4 \% \pm 0,5$. O menor valor médio do teor de gordura no $\mathrm{L}_{3}$, possivelmente, se deve à heterogeneidade entre peças de queijo de um mesmo lote de processamento. Todas as amostras dos diferentes lotes investigados apresentaram teores de gordura variando entre $27,1 \% \pm 0,6$ e $28,4 \% \pm 0,5$, atendendo aos requisitos legais; com tais teores, podem ser classificadas como queijo semigordo (BRASIL, 1996). Apesar da diferença no teor de gordura dos diferentes lotes, a variação observada é considerada pequena, inerente à variabilidade normal do processo industrial.

Os menores teores de nitrogênio $(4,61 \% \pm 0,14)$ e proteína total $(28,78 \% \pm 0,90)$ foram observados nas amostras de queijo referente ao $\mathrm{L}_{1}$, provavelmente, em consequência de menores teores de nitrogênio encontrados no leite empregado na produção deste lote, cujo valor foi de $2,54 \% \pm 0,03$. Houve diferença significativa ( $\mathrm{p}>0,05)$ no teor de sal dos queijos dos diferentes lotes (Tabela 2), com valores oscilando de $0,97 \%$ $\pm 0,04\left(\mathrm{~L}_{1}\right)$ a $1,06 \% \pm 0,01\left(\mathrm{~L}_{3}\right)$.

A análise da acidez ao longo do período de 180 dias de maturação demonstrou diferença estatística entre os lotes analisados $(\mathrm{p}<0,05)$. A acidez do queijo é um fator importante para assegurar o desenvolvimento da microbiota lática, bem

Tabela 1. Caracterização* físico-química do leite pasteurizado empregado no processamento do queijo Parmesão comercial.

\begin{tabular}{lccc}
\hline \multicolumn{1}{c}{ Análises } & L1 & L2 & L3 \\
\hline Acidez $\left({ }^{\circ} \mathrm{D}\right)$ & $15,76 \pm 0,14^{\mathrm{c}}$ & $17,05 \pm 0,49^{\mathrm{b}}$ & $18,33 \pm 0,42^{\mathrm{a}}$ \\
Crioscopia $\left({ }^{\circ} \mathrm{H}\right)$ & $-0,575 \pm 0,0^{\mathrm{a}}$ & $-0,575 \pm 0,01^{\mathrm{a}}$ & $-0,576 \pm 0,01^{\mathrm{a}}$ \\
Densidade $\left(\mathrm{g} \cdot \mathrm{mL}^{-1}\right)$ & $1,031 \pm 0,01^{\mathrm{a}}$ & $1,028 \pm 0,01^{\mathrm{a}}$ & $1,027 \pm 0,01^{\mathrm{a}}$ \\
Gordura $(\%)$ & $3,2 \pm 0,1^{\mathrm{a}}$ & $2,2 \pm 0,8^{\mathrm{b}}$ & $2,2 \pm 0,1^{\mathrm{b}}$ \\
EST (\%) & $9,740 \pm 0,010^{\mathrm{b}}$ & $9,900 \pm 0,010^{\mathrm{a}}$ & $9,740 \pm 0,010^{\mathrm{b}}$ \\
Presença de antibiótico & Negativo & Negativo & Negativo \\
\hline
\end{tabular}

${ }^{*}$ Média da triplicata; ${ }^{a, b, c l e t r a s ~ d i f e r e n t e s ~ n a ~ m e s m a ~ l i n h a ~ i n d i c a m ~ d i f e r e n c ̧ a ~ s i g n i f i c a t i v a ~}(\mathrm{p}<0,05)$. 
como manter efetiva as diferentes reações enzimáticas durante a maturação do queijo (SALÄUN; MIETTONB; GAUCHERON, 2005).

A evolução da acidez titulável (Figura 2) demonstra lento desenvolvimento até 90 dias e aumento mais acentuado aos 120 e 180 dias de maturação nas amostras de queijo referente ao $\mathrm{L}_{2}$, com valores médios oscilando entre $0,56 \% \pm 0,02$ (30 dias) e $1,77 \% \pm 0,01$ (180 dias). A Figura 2 também revela o aumento do teor de acidez com valores mínimos de 0,68\% $\pm 0,01$ e $0,56 \% \pm 0,01$ e valores máximos de $1,53 \% \pm 0,01$ e 1,54\% $\pm 0,02$, para as amostras provenientes dos $\mathrm{L}_{1}$ e $\mathrm{L}_{3}$, respectivamente. Além da conversão de lactose em ácido lático, a evolução da acidez pode estar associada à proteólise, pela liberação de peptídeos e aminoácidos, que possuem porções $\mathrm{N}$ e C-terminal livres (McSWEENEY, 2004; SALÄUN; MIETTONB; GAUCHERON, 2005).

Também foi possível observar pequenas diferenças na conversão dos componentes do leite durante o período de estocagem refrigerada. Houve aumento significativo dos teores de tirosina (Tyr) e triptofano (Trp) $(\mathrm{p}<0,05)$ na matriz dos queijos dos diferentes lotes e nos diferentes períodos investigados (Figuras 3 e 4). A amostra do queijo $\mathrm{L}_{3}$ apresentou

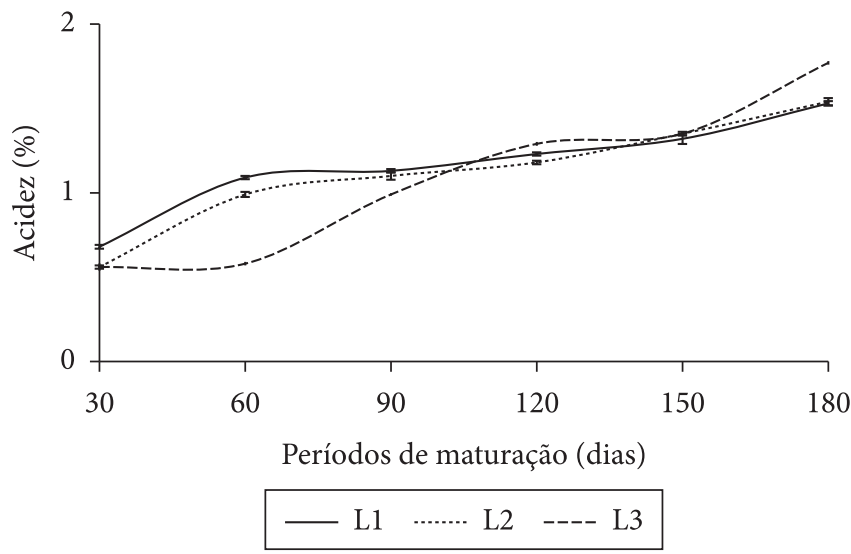

Figura 2. Evolução da acidez titulável (\%) no queijo Parmesão maturado a $12{ }^{\circ} \mathrm{C}$ durante 180 dias. o maior teor de tirosina $\left(322,54 \mathrm{mg} .100 \mathrm{~g}^{-1} \pm 0,01\right)$ e os teores de triptofano atingiram o equivalente a $97,43 \mathrm{mg} .100 \mathrm{~g}^{-1} \pm 0,01$, após 180 dias de maturação.

Durante a maturação, em razão do dinamismo dos eventos proteolíticos, é comum o aumento da concentração dos aminoácidos tirosina e triptofano na matriz do queijo (FURTADO, 2005). Em queijos duros como o Parmesão, a

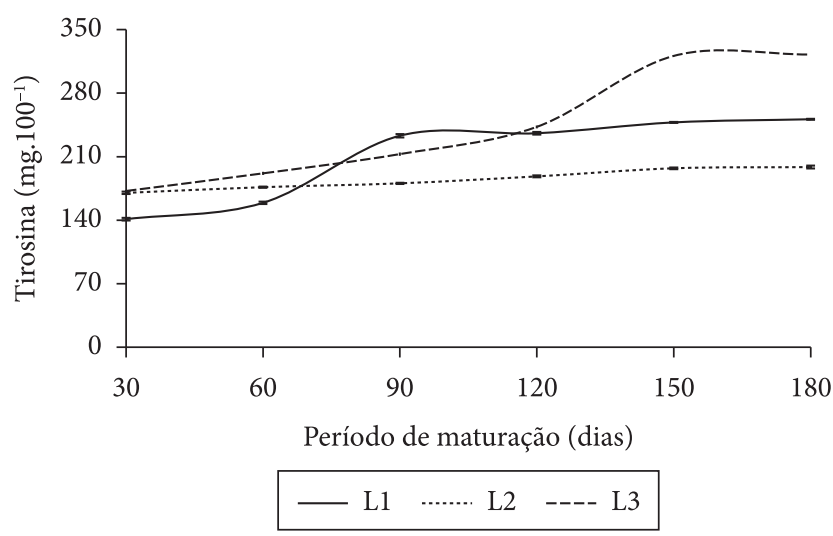

Figura 3. Evolução do teor de tirosina (mg. $\left.100 \mathrm{~g}^{-1}\right)$ no queijo Parmesão maturado a $12{ }^{\circ} \mathrm{C}$ durante 180 dias.

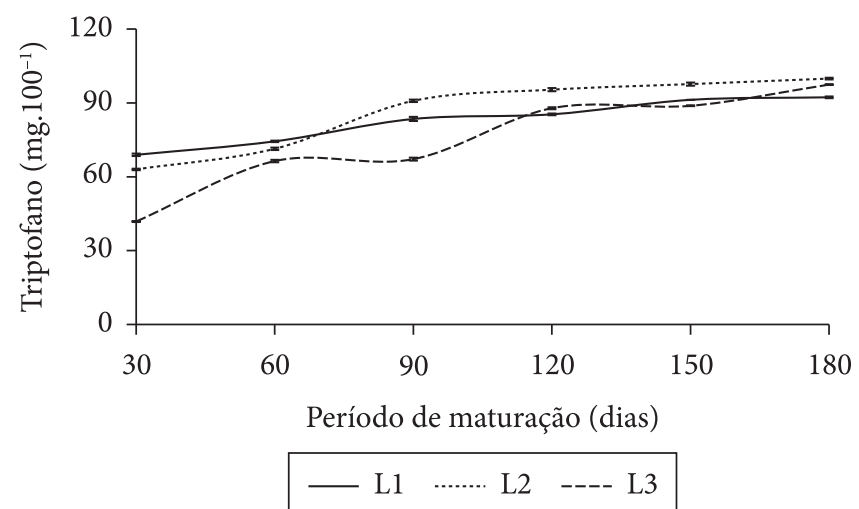

Figura 4. Evolução do teor de triptofano (mg.100 g $\mathrm{g}^{-1}$ ) no queijo Parmesão maturado a $12{ }^{\circ} \mathrm{C}$ durante 180 dias.

Tabela 2. Caracterização* físico-química das amostras de queijo Parmesão maturado a $12{ }^{\circ} \mathrm{C}$ durante 180 dias.

\begin{tabular}{|c|c|c|c|}
\hline \multirow[t]{2}{*}{ Amostras } & \multicolumn{3}{|c|}{ Lotes } \\
\hline & 1 & 2 & 3 \\
\hline Atividade de água & $0,976 \pm 0,011^{\mathrm{ab}}$ & $0,975 \pm 0,010^{\mathrm{b}}$ & $0,979 \pm 0,010^{\mathrm{a}}$ \\
\hline Umidade (\%) & $31,28 \pm 0,79^{b}$ & $30,96 \pm 0,78^{b}$ & $30,21 \pm 0,82^{\mathrm{a}}$ \\
\hline Gordura (\%) & $28,4 \pm 0,5^{\mathrm{a}}$ & $28,2 \pm 0,3^{\mathrm{a}}$ & $27,1 \pm 0,6^{\mathrm{b}}$ \\
\hline Gordura no extrato seco $(\%)$ & $41,32 \pm 0,35^{\mathrm{a}}$ & $40,84 \pm 0,50^{\mathrm{b}}$ & $38,83 \pm 0,87^{c}$ \\
\hline Nitrogênio total (\%) & $4,61 \pm 0,14^{\mathrm{b}}$ & $4,91 \pm 0,20^{\mathrm{a}}$ & $4,68 \pm 0,20^{\mathrm{b}}$ \\
\hline Proteína total (\%) & $28,78 \pm 0,90^{\mathrm{b}}$ & $30,68 \pm 0,56^{\mathrm{a}}$ & $29,25 \pm 1,36^{\mathrm{b}}$ \\
\hline Cinzas (\%) & $4,18 \pm 0,15^{\mathrm{a}}$ & $4,39 \pm 0,20^{b}$ & $4,43 \pm 0,11^{\mathrm{c}}$ \\
\hline Sal (\%) & $0,97 \pm 0,04^{\mathrm{c}}$ & $1,03 \pm 0,02^{\mathrm{b}}$ & $1,06 \pm 0,01^{\mathrm{a}}$ \\
\hline
\end{tabular}

${ }^{\star}$ Média de três determinações; ${ }^{\mathrm{a}, \mathrm{b}}$ letras diferentes na mesma linha indicam diferença significativa $(\mathrm{p}<0,05)$. 
elevada concentração de tirosina pode induzir a formação de pigmentos brancos na superfície do queijo, permitindo também detectar, ao paladar, a presença de cristais.

A proteólise é o mais complexo e importante dos eventos primários que ocorrem durante a maturação da maioria dos queijos (McSWEENEY; SOUSA, 2000). A proteólise contribui para a maturação de quatro formas: a) contribuição direta para o sabor por meio da liberação de aminoácidos e peptídeos (alguns podem conferir sabores indesejáveis - off-flavors, principalmente amargor), ou contribuição indireta, por meio do catabolismo dos aminoácidos e aminas, ácidos, tióis, etc; b) maior liberação de compostos sápidos durante a mastigação; c) alteração do $\mathrm{pH}$ em função da formação de amônia; d) alterações na textura, provenientes da quebra da rede de proteínas, aumentando o pH e conferindo maior ligação da água com grupos carboxil e amino formados (FOX et al., 1997).

Os teores médios de nitrogênio solúvel em pH 4,6 ( $\left.\mathrm{NS}_{\mathrm{pH} 4,6}\right)$ após 30 dias de maturação foram semelhantes em todos os lotes (máximo de $0,25 \% \pm 0,01$ ). Ao término de 180 dias de maturação, observaram-se maiores teores de $\mathrm{NS}_{\mathrm{pH} 4,6}$, atingindo valores de até $0,91 \% \pm 0,02\left(\mathrm{~L}_{3}\right)$. Os teores de nitrogênio não proteico ou solúvel em TCA $12 \%\left(\mathrm{NS}_{\mathrm{TCA}}\right)$ nas amostras variaram de $0,16 \% \pm 0,02$ a $0,18 \% \pm 0,01$, após 30 dias de maturação. Após 180 dias de maturação, a amostra $\mathrm{L}_{2}$ apresentou o maior teor médio de $\mathrm{NS}_{\mathrm{TCA}}(0,61 \% \pm 0,05)$.

O índice de extensão da maturação (IEM) caracterizase pela quantificação de substâncias nitrogenadas solúveis acumuladas durante o processo e são expressas como percentual do nitrogênio total. Este índice reflete a atuação das enzimas do coalho na degradação da caseína. O coalho produz, sobretudo, peptídeos de pesos moleculares médio e baixo, que vêm compor o nitrogênio solúvel em pH 4,6 (MINUSSI, 1994); note-se que, de acordo com Lemieux e Simard (1991), os peptídeos de gosto amargo são normalmente encontrados nessa fração.

No decorrer da maturação, houve liberação gradativa de nitrogênio solúvel em pH 4,6, em decorrência da proteólise, sendo os maiores valores de IEM registrados após 30 dias $(5,69 \% \pm 0,01)$ na amostra $L_{1}$ e após 180 dias $(19,70 \% \pm 0,30)$ na amostra $\mathrm{L}_{3}$ (Figura 5).

As substâncias nitrogenadas de peso molecular baixo, acumuladas durante a maturação, constituem o índice de profundidade da maturação (IPM). Esse índice é diretamente proporcional à ação das endo e exo peptidases bacterianas (descarboxilases e desaminases) que venham a liberar aminoácidos e outros compostos nitrogenados, que contribuem para o sabor típico de cada queijo. Entende-se, ainda, que seja um importante instrumento para a avaliação da atividade peptidolítica da cultura lática (MINUSSI, 1994).

Houve degradação da caseína com liberação de nitrogênio não proteico (NNP), como pode ser observado pela evolução gradativa do IPM durante os 180 dias de maturação (Figura 6). O menor valor foi $3,26 \% \pm 0,11$, encontrado na amostra $L_{2}$ aos 30 dias, e o maior valor na amostra $\mathrm{L}_{1}$, com $12,30 \% \pm 0,15$ após
180 dias de maturação. Estes valores quantificam a evolução da proteólise, bem como a atividade da cultura lática no queijo Parmesão. Durante a maturação, substâncias nitrogenadas como aminoácidos, oligopeptídeos e aminas, resultantes dos processos bioquímicos - são acumuladas na matriz do queijo, refletindo diretamente nos atributos de aroma e sabor do produto final (FURTADO, 2005).

Segundo Perotti et al. (2005), as concentrações de tirosina normalmente apresentam a mesma tendência dos índices de extensão e profundidade da maturação. A evolução dos índices de extensão (IEM) e profundidade da maturação (IPM) foi significativa entre os diferentes períodos de maturação $(\mathrm{p}<0,05)$.

\subsection{Qualidade higiênico-sanitária do leite pasteurizado e do queijo Parmesão maturado}

O perfil microbiológico e físico-químico do leite são parâmetros primordiais à qualidade do Parmesão (FOX et al., 1997; FURTADO, 2005). Neste estudo (Tabela 3), a maior

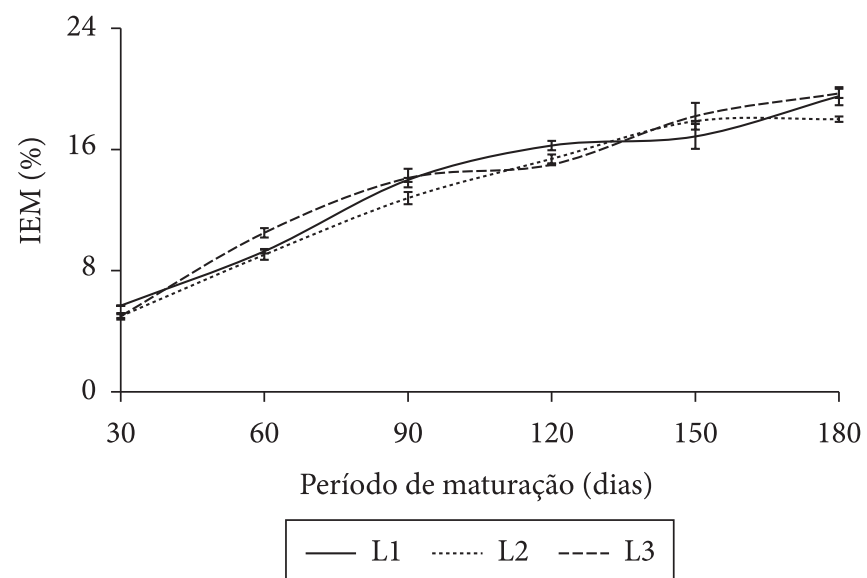

Figura 5. Evolução do índice da extensão da maturação (IEM \%) do queijo Parmesão maturado a $12^{\circ} \mathrm{C}$ durante 180 dias.

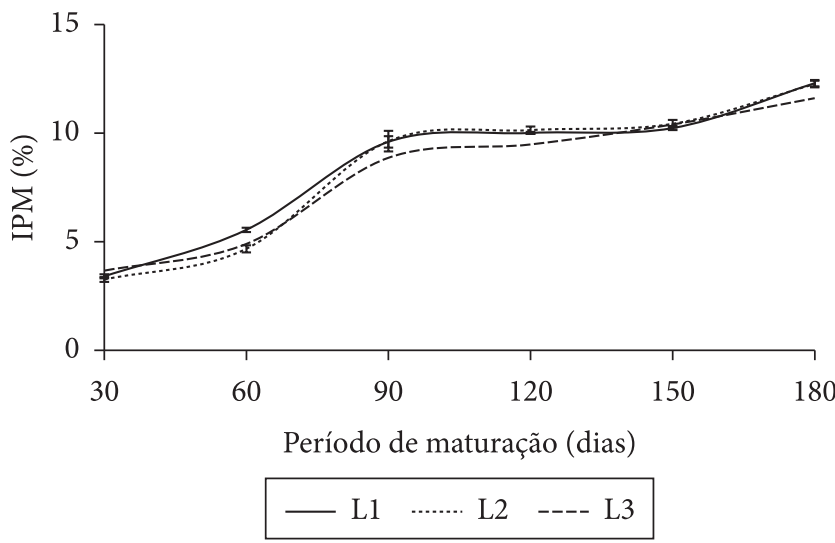

Figura 6. Evolução do índice da profundidade da maturação (IPM \%) do queijo Parmesão maturado a $12{ }^{\circ} \mathrm{C}$ durante 180 dias. 
Tabela 3. Bioindicadores de contaminação $\left(U F C \cdot \mathrm{mL}^{-1}\right)^{\star}$ nas amostras de leite pasteurizado utilizado na fabricação do queijo Parmesão comercial.

\begin{tabular}{|c|c|c|c|c|}
\hline Amostras & $\begin{array}{c}\text { Coliformes } \\
\text { totais }\end{array}$ & $\begin{array}{c}\text { Coliformes } \\
\text { termotolerantes }\end{array}$ & $\begin{array}{l}\text { Contagem padrão } \\
\text { de mesófilos }\end{array}$ & $\begin{array}{c}S . \text { coagulase } \\
\text { positiva }\end{array}$ \\
\hline $\mathrm{L}_{1}$ & $<1,0 \times 10^{0 \mathrm{a}}$ & $<1,0 \times 10^{0 a}$ & $1,1 \times 10^{0 a}$ & $<1,0 \times 10^{1 \mathrm{a}}$ \\
\hline $\mathrm{L}_{2}$ & $<1,0 \times 10^{0 \mathrm{a}}$ & $<1,0 \times 10^{0 \mathrm{a}}$ & $1,0 \times 10^{0 \mathrm{a}}$ & $<1,0 \times 10^{1 \mathrm{a}}$ \\
\hline $\mathrm{L}_{3}$ & $<1,0 \times 10^{0 \mathrm{a}}$ & $<1,0 \times 10^{0 \mathrm{a}}$ & $1,3 \times 10^{0 a}$ & $<1,0 \times 10^{1 \mathrm{a}}$ \\
\hline
\end{tabular}

${ }^{*}$ Média da triplicata; ${ }^{a}$ não houve diferença estatística significativa $(\mathrm{p}>0,05)$.

população média $(\mathrm{p}>0,05)$ de micro-organismos mesofílicos foi de $1,3 \times 10^{0}$ UFC. $\mathrm{mL}^{-1}$ no leite pasteurizado utilizado para fabricação do terceiro processamento $\left(\mathrm{L}_{3}\right)$, o que demonstra medidas operacionais corretas durante o beneficiamento do leite (JAY, 2005). Os valores médios para coliformes totais e Escherichia coli foram $<1,0 \times 10^{0}$ UFC. $\mathrm{mL}^{-1}$, não sendo notificada a presença de Salmonella sp. $(\mathrm{p}>0,05)$.

Os resultados das análises microbiológicas do leite pasteurizado empregado no processamento do queijo Parmesão comercial indicam conformidade da amostra aos padrões exigidos pela Instrução Normativa 51 - IN 51, que recomenda valor máximo de $8,0 \times 10^{4} \mathrm{NMP} . \mathrm{mL}^{-1}$ para bactérias mesófilas, $2,0 \times 10^{0} \mathrm{NMP} \cdot \mathrm{mL}^{-1}$ para coliformes termotolerantes, valor inferior a 5,0 $\times 10^{0} \mathrm{NMP} . \mathrm{mL}^{-1}$ para coliformes totais e ausência de Salmonella sp., em $25 \mathrm{~mL}$ do leite fluido pós-pasteurização (BRASIL, 2002).

No decorrer dos 180 dias de maturação, a maior população de coliformes totais foi registrada na amostra de queijo Parmesão proveniente do primeiro lote $\left(\mathrm{L}_{1}\right)$, aos 30 dias de armazenamento, com 1,2 $\times 10^{1} \mathrm{UFC}_{\text {. }}{ }^{-1}$ ( $\left.\mathrm{p}>0,05\right)$, portanto, em conformidade aos padrões legais de, no máximo, 1,0 × $10^{3}$ UFC.g-1 ${ }^{-1}$ BRASIL, 1996). Em nenhuma das amostras investigadas foi identificada Escherichia coli $\left(<1,0 \times 10^{1} \mathrm{UFC}^{-1} \mathrm{~g}^{-1}\right)$ e Staphylococcus coagulase positiva $\left(<1,0 \times 10^{2} \mathrm{UFC}^{-1}\right)$. Todas as amostras analisadas estão de acordo com os padrões preconizados pela legislação vigente, que são de no máximo 5,0 × $10^{2} \mathrm{UFC} \mathrm{g}^{-1}$ e $1,0 \times 10^{3} \mathrm{UFC} . \mathrm{g}^{-1}$, para coliformes termotolerantes e $S$. coagulase positiva, respectivamente (BRASIL, 1996).

\subsection{Análise da estrutura dos queijos por microscopia eletrônica de transmissão (MET) e numeração de inclusões cristalinas}

O estudo qualitativo das eletromicrografias revela maior distribuição de proteínas e gorduras, seguida da incidência de bactérias. Durante o período de estocagem, foi possível observar a interação das culturas láticas com os glóbulos de gordura (Figura 7a, b, h). As eletromicrografias revelam o arranjo do micro-organismo junto ao lipídeo. Parker et al. (1998) observaram inserções das bactérias na matriz proteica, especialmente nas junções do coágulo. Além disso, as células estavam diretamente em contato com as membranas dos glóbulos de gordura ou localizadas na interface proteínagordura. A presença de bactérias láticas na porção lipídica também foi observada por Dean, Berridge e Mabbitt (1959) e Lopez et al. (2006) em queijos Cheddar e Emmental, respectivamente.

Na Figura 7, no período de 30 dias de maturação (Figura 7a, b), os glóbulos de gordura apresentam tamanhos maiores quando comparados àqueles observados nos demais períodos (Figuras 7f, g, h, i). Possivelmente, o surgimento dos pequenos glóbulos de gordura pode ser consequência da ação de lipases microbianas ativas na matriz do queijo durante a maturação (COLLINS; McSWEENEY; WILKINSON, 2003) e/ou provenientes do tratamento aplicado no processamento desse derivado lácteo (LOPEZ, 2005; LOPEZ; CAMIER; GASSI, 2007). Embora o tratamento térmico do leite seja indispensável para garantir a qualidade sanitária na fabricação de queijos, quando é realizado de forma severa, pode afetar a estrutura do coágulo, sendo perceptível, mais tarde, na microestrutura do produto (PEREIRA; GOMES; MALCATA, 2009).

A microestrutura do queijo Parmesão aos 90 dias de maturação (Figura 7d) demonstrou a incidência de inclusões cristalinas, apresentando morfotipo oval (MADADLOU; KHOSROSHAHI; MOUSAVI, 2005), sendo possível distinguir o núcleo, apresentando aspecto desorganizado (FRAU et al., 1997; YE et al., 2004), e o córtex, com morfologia radial laminar (JUNQUEIRA; CARNEIRO, 2004). Também há ocorrência de debris (Figura 7e), evidenciando a morte celular das culturas láticas (PAGALA et al., 2002) na metade do período de maturação estudado.

A amostra maturada por 180 dias (Figura 7i) demonstra maior modificação da matriz proteica, indicando possivelmente a efetividade da proteólise (LAWRENCE; GILLES; CREAMER, 1983), pelas proteases e peptidases nos queijos (McSWEENEY, 2004). Geralmente, em queijos Parmesão submetidos à maturação desprovidos de embalagem, é nítido o surgimento de uma matriz proteica densa, proveniente da redução gradual da umidade causada pela evaporação da água na superfície do queijo.

As inclusões foram detectadas em todas as amostras e em todos os períodos de maturação, em valores que oscilaram de 0,13 cristais. $\mathrm{kg}^{-1}$ a 0,18 cristais. $\mathrm{kg}^{-1}$. Houve um aumento na concentração de cristais das amostras maturadas por 60 dias, com valor de 0,18 cristais. $\mathrm{kg}^{-1}$, sendo considerando também o maior valor encontrado. Não foi observada uma relação direta entre o número de cristais com o período de maturação. Possivelmente, o aumento da amostragem permitiria visualizar essa correlação. Botazzi, Battistotti e Bianchi (1982) observaram 

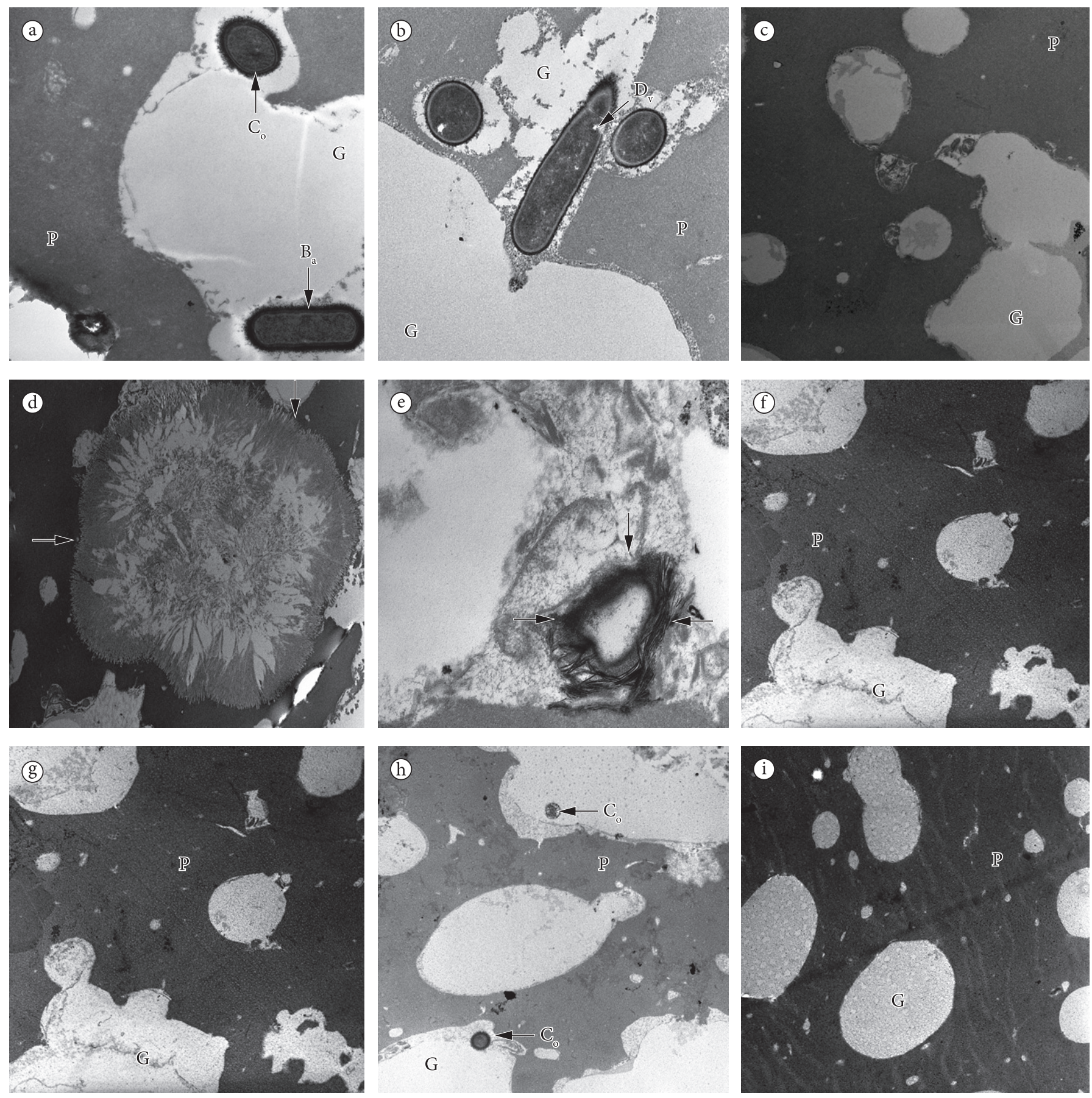

Figura 7. Microestrutura do queijo Parmesão maturado a $12^{\circ} \mathrm{C}$. a) $\mathrm{L}_{1}$ maturado por 30 dias $12.930 \times, \mathrm{C}_{\mathrm{o}}$ : cocos, $\mathrm{B}_{\mathrm{a}}$ : bacilo; b) $\mathrm{L}_{2}$ maturado por 30 dias 6.000×, Dv: divisão celular; c) $\mathrm{L}_{2}$ maturado por 60 dias 6.000×; d) $\mathrm{L}_{2}$ maturado por 60 dias $3.597 \times$, setas: inclusão cristalina; e) $\mathrm{L}_{1}$ maturado por 90 dias $6.000 \times$, setas: debris; f) $\mathrm{L}_{1}$ maturado por 90 dias $27800 \times$; g) L maturado por 120 dias $6.000 \times$; h) $\mathrm{L}_{2}$ maturado por 150 dias $6.000 \times$; e i) $\mathrm{L}_{1}$ maturado por 180 dias $6.000 \times$; G: glóbulos de gordura; P: matriz proteica.

em queijo Grana maturado por período superior a seis meses, valores entre 30 cristais. $\mathrm{m}^{-2}$ e 35 cristais. $^{-2}$. Queijos duros como o Parmesão podem apresentar incidência de tirosinato de cálcio, aspecto favorável ao queijo, uma vez que reflete o grau de maturação desse produto (FURTADO, 2005).

Os cristais de cálcio presentes na matriz do queijo, quando em contato direto com nitrato de prata, adquirem uma coloração amarronzada, facilitando sua identificação e enumeração. A
Figura 8 demonstra a presença desses cristais no queijo após 30 dias de maturação.

Os resultados demonstram que o método de von Kossa é uma valiosa ferramenta para análise microscópica de cristais de cálcio em queijo. Experimentos adicionais podem ser implementados para diferenciar os subtipos desses cristais e correlacioná-los com aspectos de qualidade ou defeitos dos queijos maturados. 


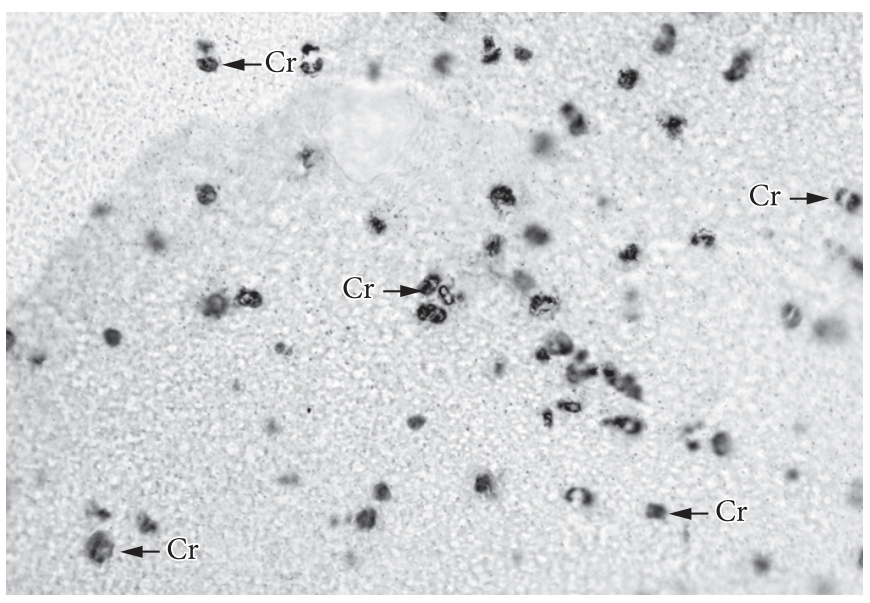

Figura 8. Microestrutura do queijo Parmesão maturado a $12^{\circ} \mathrm{C}$ durante 30 dias $\left(\mathrm{C}_{\mathrm{r}}\right.$ : cristais de cálcio $220 \times$ ).

\section{Conclusões}

Todas as amostras exibiram características físico-químicas e microbiológicas de acordo com a legislação brasileira. Ocorreu aumento na acidez titulável, nos índices de extensão e profundidade da maturação e nos teores de tirosina e triptofano ao longo da maturação, em todos os lotes. A evolução da maturação também pode ser observada por alterações na microestrutura. A presença de inclusões cristalinas de morfotipo oval, a interação entre as culturas starter e os glóbulos de gordura, debris e uma matriz densa foram observadas no final da maturação.

\section{Agradecimentos}

À Fundação de Amparo à Pesquisa do Estado de São Paulo - FAPESP, pelo auxílio financeiro para a realização do estudo; ao Laticínio Tirolez, unidade de Arapuá-MG, por ceder as amostras comerciais de queijo Parmesão, e ao Professor Ms. Gismar Vieira Silva, pelo auxílio no tratamento estatístico dos resultados experimentais.

\section{Referências bibliográficas}

ARYANA, K. J.; HENK, M. C. Rapid method of cheese processing for microflora and microstructural studies by electron microscopy. Journal of Rapid Methods and Automation in Microbiology, v. 12, n. 3, p. 199-206, 2004. http://dx.doi.org/10.1111/j.1745-4581.2004. tb00063.x

ASSOCIAÇÃO BRASILEIRA DAS INDÚSTRIAS DE QUEIJOS ABIQ. Queijos - Mercado total brasileiro. 2010.

ASSOCIATION OF OFFICIAL ANALYTICAL CHEMISTS - AOAC. Dairy Products. In: AOAC. Official Methods of Analysis. 16th ed. Arlington: AOAC, 1997.

AWAD, R. A.; ABDEL-HAMID, L. B.; EL-SHABRAWY, S. A. Texture and microstructure of block type processed cheese with formulated emulsifying salt mixtures. Lebensmittel Wissenschaft und Technologie - Food Science, v. 35, n. 1, p. 54-61, 2002.

BOTTAZZI, V.; BATTISTOTTI, B.; BIANCHI, F. The microscopic crystalline inclusions in Grana cheese and their X-ray microanalysis. Milchwissenschaft, v. 37, n. 10, p. 577-580, 1982.
BRASIL. Ministério da Agricultura, Pecuária e Abastecimento. Regulamentos Técnicos de Identidade e Qualidade de Produtos Lácteos. Diário Oficial da República Federativa do Brasil, 11 mar. 1996. Seção 1, p. 3977. Disponível em: <http://www.agricultura. gov.br>.

BRASIL. Ministério da Agricultura, Pecuária e Abastecimento. Regulamento Técnico de Identidade e Qualidade de Queijo Parmesão. Portaria 353 de 4 de setembro de 1997. Diário Oficial da República Federativa do Brasil, 08 set. 1997. Seção 1, p. 19684. Disponível em: <http://www.agricultura.gov.br>.

BRASIL. Ministério da Agricultura, Pecuária e Abastecimento. Instrução Normativa n ${ }^{\circ} 51$. Diário Oficial República Federativa do Brasil, 20 set. 2002. Seção 1, p. 13. Disponível em: <http://www. agricultura.gov.br>.

BROMBERG, R. et al. Isolation of bacteriocin-producing lactic acid bacteria from meat and meat products and its spectrum of inhibitory activity. Brazilian Journal of Microbiology, v. 35, p. 137-144, 2004. http://dx.doi.org/10.1590/S1517-83822004000100023

CANDIOTI, M. C. et al. Reggianito Argentino cheese: influence of Lactobacillus helveticus strains isolated from natural whey cultures on cheese making and ripening process. International Dairy Journal, v. 12, n. 1, p. 923-931, 2002. http://dx.doi.org/10.1016/ S0958-6946(02)00115-2

CASE, R. A.; BRADLEY JUNIOR, R. L.; WILLIAMS, R. R. Chemical and Physical Methods. In: AMERICAN PUBLIC HEALTH ASSOCIATION. Standard Methods for the Examination of Dairy Products. 15. ed. Washington: APA, 1985. p. 327-404.

COLLINS, Y. F.; McSWEENEY, P. L. H.; WILKINSON, M. G. Evidence for a relationship between autolisys of starter bacteria and lypolisys in Cheddar cheese. Journal of Dairy Reserch, v. 70, n. 1, p. 105-113, 2003. PMid:12617399. http://dx.doi.org/10.1017/ S0022029902005915

DABOUR, N. et al. Application of ruthenium red and colloidal goldlabeled lectin for the visualization of bacterial exopolysaccharides in Cheddar cheese matrix using transmission electron microscopy. International Dairy Journal, v. 13, n. 4, p. 1-12, 2005.

DEAN, M. R.; BERRIDGE, N. J.; MABBITT, L. A. Microscopical observations on Cheddar cheese and curd. Journal of Dairy Research, v. 26, n. 1, p. 77-82, 1959. http://dx.doi.org/10.1017/ S0022029900009705

DEKLERK, D. P.; COFFEY, D. S. Quantitative determination of prostatic epithelial and stromal hyperplasia by a new technique biomorphometrics. Investigative Urology, v. 16, n. 3, p. 240-245, 1978.

FOX, P. F. et al. Biochemistry of Cheese Ripening. In: FOX, P. F. Cheese: chemistry, physics and microbiology. London: Chapman \& Hall, 1997. v.1, p. 389-439.

FRAU, M. et al. Microscopic crystalline inclusions in Mahón cheese. Food Science and Technology International, v. 3, n. 1, p. 23-47, 1997.

FURTADO, M. M. Principais problemas dos queijos: causas e prevenção. São Paulo: Metha, 2005. 200 p.

INSTITUTO ADOLFO LUTZ - IAL. Normas Analíticas do Instituto Adolfo Lutz. 3. ed. São Paulo: IAL, 1985.

INSTITUTO BRASILEIRO DE GEOGRAFIA E ESTATÍSTICA - IBGE. Pesquisa Industrial. Rio de Janeiro: IBGE, 2006. 188 p.

JAY, J. M. Microbiologia dos alimentos. 3. ed. Porto Alegre: Artmed, 2005. $711 \mathrm{p}$.

JUNQUEIRA, L. C. U; CARNEIRO, J. Histologia Básica. 10. ed. Rio de Janeiro: Guanabara Koogan, 2004. 540 p.

KELLY, A. L.; FOX, P. F. Indigenous enzymes in milk: a synopsis of future research requirements. International Dairy Journal, v. 16, n. 6, p. 707-715, 2006. http://dx.doi.org/10.1016/j.idairyj.2005.10.018 
KENNY, O. et al. Growth phase and growth medium effects on the peptidase activities of Lactobacillus helveticus. International Dairy Journal, v. 13, n. 7, p. 509-516, 2003. http://dx.doi.org/10.1016/ S0958-6946(03)00073-6

LALOY, E. et al. Influence of the fat content of Cheddar cheese on retention and localization of starters. International Dairy Journal, v. 6 , n. 7, p. 729-740, 1996. http://dx.doi.org/10.1016/09586946(95)00068-2

LAWRENCE, R. C.; GILLES, J.; CREAMER, L. K. The relationship between cheese texture and flavour. New Zealand Journal Dairy Science and Technology, v. 18, n. 3, p. 175-190, 1983.

LEMIEUX, L.; SIMARD, R. E. Bitter flavor in dairy products: a review of the factors likely to influence its development, mainly in cheese manufacture. Le Lait - Dairy Science and Technology, v. 71, n. 6, p. 599-636, 1991.

LOPEZ, C. Focus on the supramolecular structure of milk fat in dairy products. Reproduction Nutrition Development, v. 45, n. 4, p. 497-511, 2005. PMid:16045897. http://dx.doi.org/10.1051/ rnd:2005034

LOPEZ, C.; CAMIER, B.; GASSI, J. Development of the milk fat microstructure during the manufacture and ripening of Emmental cheese observed by confocal laser scanning microscopy. International Dairy Journal, v. 17, n. 3, p. 235-247, 2007. http:// dx.doi.org/10.1016/j.idairyj.2005.12.015

LOPEZ, C. et al. Lipolysis during ripening of Emmental cheese considering organization of fat and preferential localization of bacteria. Journal of Agricultural and Food Chemistry, v. 54, p. 5955-5867, 2006. PMid:16881687. http://dx.doi.org/10.1021/ jf0602141

LORTAL, S.; CHAPOT-CHARTIER, M. P. Role, mechanisms and control of lactic acid bacteria lysis in cheese. International Dairy Journal, v. 15, n. 6/9, p. 857-871, 2005. http://dx.doi.org/10.1016/j. idairyj.2004.08.024

MADADLOU, A.; KHOSROSHAHI, A.; MOUSAVI, M. E. Rheology, microstructure, and functionality of low-fat Iranian white cheese made with different concentrations of rennet. Journal of Dairy Science, v. 88, n. 9, p. 3052-3062, 2005. http://dx.doi.org/10.3168/ jds.S0022-0302(05)72986-6

MALACARNE, M. et al. Proteolysis and lipolysis of ParmigianoReggiano cheese at different ripening periods: 12, 24, 55 and 96 months. Annali di Facoltà Veterinaria di Parma, v. 26, p. 145-164, 2006.

MARILLEY, L.; CASEY, M. G. Flavours of cheese products: metabolic pathways, analytical tools and identification of producing strains. Review article. International Journal of Food Microbiology, v. 90, n. 2, p. 139-159, 2004. http://dx.doi.org/10.1016/S01681605(03)00304-0

MAZEROLLES, G. et al. Infrared and fluorescence spectroscopy for monitoring protein structure and interaction changes during cheese ripening. Le Lait - Dairy Science and Technology, v. 81, n. 4, p. 509-527, 2001.

McSWEENEY, P. L. H. Biochemistry of cheese ripening. International Journal of Dairy Technology, v. 57, n. 4, p.127-144, 2004. http:// dx.doi.org/10.1111/j.1471-0307.2004.00147.x

McSWEENEY, P. L. H.; SOUSA, M. J. Biochemical pathways for the production of flavour compounds in cheeses during ripening: A review. Le Lait - Dairy Science and Technology, v. 80, n. 3, p. 293-324, 2000.

MINUSSI, R. C. Avaliação de métodos para a aceleração da maturação de queijo Prato. 1994. 84 f. Dissertação (Mestrado em Ciência e Tecnologia de Alimentos)-Universidade Federal de Viçosa, Viçosa, 1994.

OGUNBANWO, S. T.; SANNI, A. I.; ONILUDE, A. A. Influence of cultural conditions on the production of bacteriocin by Lactobacillus brevis OG1. African Journal of Biotechnology, v. 2, n. 7, p. 179-184, 2003.

PAGALA, V. R. et al. Cellular localization of D-lactate dehydrogenase and NADH oxidase from Archaeoglobus fulgidu. Archaea, v. 1, n. 2, p. 95-104, 2002. PMCid:2685561. http://dx.doi. org/10.1155/2002/297264

PARKER, M. L. et al. The microstructure and distribution of microorganisms within mature Serra cheese. Journal of Applied Microbiology, v. 84, n. 4, p. 523-530, 1998. PMid:9633650. http:// dx.doi.org/10.1046/j.1365-2672.1998.00375.x

PEREIRA, C. I.; GOMES, A. M. P.; MALCATA, F. X. Microstructure of cheese: processing, technological and microbiological considerations. Trends in Food Science \& Technology, v. 20, n. 5, p. 213-219, 2009. PMid:21299575. http://dx.doi.org/10.1016/j. tifs.2009.02.006

PERKO, B. Lactose fermentation at Camembert, made by classic and stabilized technology. Mljekarstvo, v. 52, n. 1, p. 5-18, 2002.

PEROTTI, M. C. et al. Free fatty acid profiles of Reggianito Argentino cheese produced with different starters. International Dairy Journal, v. 15, n. 11, p. 1150-1155, 2005. http://dx.doi.org/10.1016/j. idairyj.2004.11.005

PEROTTI, M. C. et al. Substitution of natural whey starter by mixed strains of Lactobacillus helveticus in the production of Reggianito Argentino cheese. International Journal of Dairy Technology, v. 57, n. 1, p. 45, 2004. http://dx.doi.org/10.1111/j.1471-0307.2004.00128.x

PERRY, K. S. P. Queijos: Aspectos Químicos, Bioquímicos e Microbiológicos. Revista Química Nova, v. 27, n. 2, p. 293-300, 2004

ROMANI, S. et al. Physical, chemical, texture and sensorial changes of portioned Parmigiano Reggiano cheese packed under different conditions. Food Science and Technology International, v. 8, n. 4, p. 203-211, 2002.

SALÄUN, F.; MIETTONB, B.; GAUCHERON, F. Buffering capacity of dairy products. International Dairy Journal, v. 15, n. 22, p. 95-109, 2005.

SILVA, N. D; JUNQUEIRA, V. C. A.; SILVEIRA, N. Manual de métodos de análise microbiológica de alimentos. 3. ed. São Paulo: Varela, 2007. $317 \mathrm{p}$

SILVA, P. H. F. et al. Físico-Química do Leite e Derivados: Métodos Analíticos. Juiz de Fora: Oficina de Impressão, 1997. 190 p.

TRONCO, V. M. Manual para Inspeção da Qualidade do Leite. Santa Maria: Universidade Federal de Santa Maria, 1997. 166 p.

VAKALERIS, D. G.; PRICE, W. V. Rapid spectrophotometric method for measuring cheese ripening. Journal of Dairy Science, v. 42 , n. 2, p. 264-276, 1959. http://dx.doi.org/10.3168/jds.S00220302(59)90562-4

VAN DENDER, A. G. F. et al. Determinação da atividade de água de queijos usando crioscopia eletrônica. Revista do Instituto de Laticínios Cândido Tostes, v. 50, n. 3, p. 18-26, 1995.

WOLFSCHOON-POMBO, A. F. Índices de proteólise em alguns queijos brasileiros. Boletim do Leite, v. 51, n. 661, p. 1-8, 1983.

YE, A. et al. Interactions of whey proteins with milk fat globule membrane proteins during heat treatment of whole milk. Le Lait Dairy Science and Technology, v. 84, n. 3, p. 269-283, 2004.

ZONTA, E. P.; MACHADO, A. A. Sistema de análise estatística para microcomputadores. Pelotas: UFPEL, 1996. 109 p. 